Check for updates

Cite this: Chem. Sci., 2018, 9, 7540

๑ All publication charges for this article have been paid for by the Royal Society of Chemistry

Received 10th April 2018

Accepted 1st August 2018

DOI: $10.1039 / \mathrm{c} 8 \mathrm{sc} 01626 \mathrm{~g}$

rsc.li/chemical-science

\section{A soft phosphorus atom to "harden" an erbium(III) single-ion magnet $\dagger$}

\author{
Shi-Ming Chen, (D) a Jin Xiong, ${ }^{a}$ Yi-Quan Zhang, (D) ${ }^{\mathrm{b}}$ Qiong Yuan, ${ }^{\mathrm{a}}$ Bing-Wu Wang (D) *a \\ and Song Gao (D) *a
}

Beyond the lanthanide organometallic single-ion magnet $(\mathrm{SIM})(\mathrm{Cp} *) \operatorname{Er}(\mathrm{COT})^{1}\left([\mathrm{Cp}]^{-}=\right.$pentamethylcyclopentadienide; $\mathrm{COT}^{2-}=$ cyclooctatetraenide) that has a good performance, we managed to replace one coordinated carbon atom on the $\left[\mathrm{Cp}^{*}\right]^{-}$ring by a soft phosphorus atom and obtained (Dsp) $\operatorname{Er}(\mathrm{COT})$ (CCDC No. 1835955; Dsp $^{-}=3,4$-dimethyl-2,5-bis(trimethylsilyl)phospholyl) whose sandwich structure is reported here for the first time. This substitution results in a remarkable change of magnetic dynamics. It exhibits slow magnetic relaxation under a zero applied direct current (DC) magnetic field with an energy barrier $\left(\Delta / k_{\mathrm{B}}\right)$ of $358 \mathrm{~K}$ and magnetic hysteresis up to $9 \mathrm{~K}$, both of which are higher than those of $(\mathrm{Cp} *)$ Er(COT). With the descended local symmetry of (Dsp)Er(COT), the energy barrier and blocking temperature $\left(T_{\mathrm{B}}\right)$ both improve unexpectedly and are among the highest ones in Er(III)-based single-molecule magnets (SMMs)
Magnetism is one of many basic physical properties of molecules which we chemists could explore and understand by studying the geometrical and electronic structures. ${ }^{2}$ This area has flourished as a lively crossroad for physics, chemistry and materials science. Single-molecule magnets (SMMs) are one of the most cutting-edge fields in molecular magnetism thriving from the inception of the noted $\left\{\mathrm{Mn}_{12}\right\}$ in 1993. ${ }^{3}$ SMMs belong to a class of molecules which can exhibit slow magnetic relaxation purely of a molecular origin rather than the collective behavior facilitated by magnetic exchange coupling in ensembles through a 3D network. ${ }^{4}$ If there's only a single spin center, they're also noted as single-ion magnets (SIMs). ${ }^{4 c}$ The famed $\left[\mathrm{Pc}_{2} \mathrm{~Tb}\right]^{-}\left([\mathrm{Pc}]^{2-}=\right.$ dianion of phthalocyanine) opened the prosperous stage to lanthanide SIMs (Ln-SIMs) because of their unparalleled single-ion anisotropy due to unquenched orbital angular momentum especially for heavy lanthanide ions. ${ }^{5,6}$ The success of $\left[\mathrm{Pc}_{2} \mathrm{~Tb}\right]^{-}$offers an intriguing possibility for molecular spintronics. ${ }^{7}$ In 2011, an organometallic SIM (Cp*)Er(COT) ${ }^{1 a}$ was reported by our group. It shows two magnetic relaxation processes under a zero applied DC magnetic field arising from two statically disordered conformers with energy barriers of 197 and $323 \mathrm{~K}$, respectively, which were several times higher than

\footnotetext{
${ }^{a}$ Beijing National Laboratory of Molecular Science, State Key Laboratory of Rare Earth Materials Chemistry and Applications, College of Chemistry and Molecular Engineering, Peking University, Beijing 100871, P. R. China. E-mail: wangbw@pku. edu.cn; gaosong@pku.edu.cn

bJiangsu Key Laboratory for NSLSCS, School of Physical Science and Technology, Nanjing Normal University, Nanjing 210023, P. R. China

$\dagger$ Electronic supplementary information (ESI) available. CCDC 1835954-1835958. For ESI and crystallographic data in CIF or other electronic format see DOI: $10.1039 / \mathrm{c} 8 \mathrm{sc} 01626 \mathrm{~g}$
}

those of cluster-based SMMs at that time. From then on concerted efforts have been made toward Ln-SIMs with a high energy barrier $\left(\Delta / k_{\mathrm{B}}\right)$ for the reversal of magnetic quantum states and magnetic blocking temperature $\left(T_{\mathrm{B}}\right) .^{8}$

In order to construct a good SIM, hard bases containing $\mathrm{O}$ or $\mathrm{N}$ coordinating atoms are often introduced to enhance the uniaxial ligand field and hence the zero field splitting which is the main source of Ising-type anisotropy for Ln-SIMs. ${ }^{8,9}$ But in this work we do exactly the opposite. Based on $\left(\mathrm{Cp}^{*}\right) \operatorname{Er}(\mathrm{COT})$, using a soft phosphorus analogue of the $\mathrm{Cp}^{-}$ligand - a phosphacyclopentadienyl (phospholyl) ligand - can improve the SIM performance unexpectedly.

Phospholyl ligands have already become well-established alternatives to cyclopentadienyl $\left(\mathrm{Cp}^{-}\right)$groups ${ }^{10}$ in organometallic chemistry for polymerization catalysis ${ }^{11}$ and have captivated synthetic chemists in coordination chemistry. ${ }^{12}$ Thanks to the isolobal analogy ${ }^{13}$ between $-\mathrm{C}(\mathrm{H} / \mathrm{Me})$ and phosphorus, phospholyl ligands can retain aromaticity to some extent relative to $\mathrm{Cp}^{-}$or $\left[\mathrm{Cp}^{*}\right]^{-} .^{14,15}$ And they still tend to keep their $\eta^{5}$ mode like $\mathrm{Cp}^{-}$in coordinating with Ln ions in most cases. ${ }^{16}$ However, according to the theory of hard and soft acids and bases, ${ }^{17}$ the substitution of $\mathrm{C}$ by a larger and floppy $\mathrm{P}$ makes them softer bases and poor $\pi$-donors. ${ }^{18,19}$ This substitution will undoubtedly lead to the lowered affinity of phospholyl ligands with some high-valent metal ions Ln(III) for instance which act as hard acids. Furthermore, in Dsp ${ }^{-}$two electron-withdrawing groups $-\mathrm{SiMe}_{3}$ further reduce the nucleophilicity. Meanwhile, they are less inclined to be in $\eta^{1}$ coordination mode using the lone-pair electrons of $\mathrm{P}$ atoms for the lower affinity of $\mathrm{P}$ with $\mathrm{Ln}$ ions with only three exceptions. ${ }^{20}$ So we can safely replace the $\mathrm{Cp}^{-}$ring by a phospholyl group and keep the same coordination 
mode, and make a rational structural comparison between the two. For Ln(II), the lower oxidation state, larger ionic radius and hence softer acidity make it more easily bind to phospholyl ligands. Phospholyl Ln(II) complexes can be synthesized either by salt metathesis ${ }^{19}$ or by a redox reaction between metal Ln and 1,1'-biphospholyls. ${ }^{21}$ However, especially for heavy Ln(III), it's a different scenario. Comparatively very few phospholyl heavy Ln(III) complexes have been successfully synthesized and structurally characterized so far, such as, (Dtp) ${ }_{2} \mathrm{TmI}$ (Dtp $^{-}=$ 3,4-dimethyl-2,5-di-tert-butyl phospholyl), ${ }^{22}\left\{(\mathrm{Htp})_{2} \mathrm{TmI}_{2}\right\}_{2}$ Htp $^{-}$ $=2,5$-di-tert-butyl phospholyl), ${ }^{22}$, (Dtp) ${ }_{2}$ DyI,${ }^{23}\left\{(\mathrm{Dsp})_{2} \mathrm{DyI}\right\}_{2}$ (ref. 23) and $\left\{(\mathrm{Dtp})_{2} \mathrm{Tm}(\mu-\mathrm{S})\right\}_{2} \cdot{ }^{24}$ Moreover, the single crystal structure of sandwiched (phospolyl)Ln(COT) has not been reported yet, and only two close examples of early $\operatorname{Ln}(\mathrm{III})$ compounds (Dsp)Nd(COT)(THF) $)^{25}$ and (Tmp)Nd(COT) $\left[\mathrm{OP}\left(\mathrm{NMe}_{2}\right)_{3}\right]^{26}$ $\left(\mathrm{Tmp}^{-}=\right.$tetramethyl phospholyl) were found but not in a double-decker structure in the presence of solvent THF and other ancillary ligands $\mathrm{OP}\left(\mathrm{NMe}_{2}\right)_{3}$. In this work, we obtained a phospholyl heavy $\operatorname{Ln}(\mathrm{III})$ complex (Dsp)Er(COT) with a sandwich structure.

With the change of coordination capability described above when phospholyl ligands replace $\left[\mathrm{Cp}^{*}\right]^{-}$, ligand field and consequently the electronic structure of the whole complexes will be different accordingly, which may bring about significant
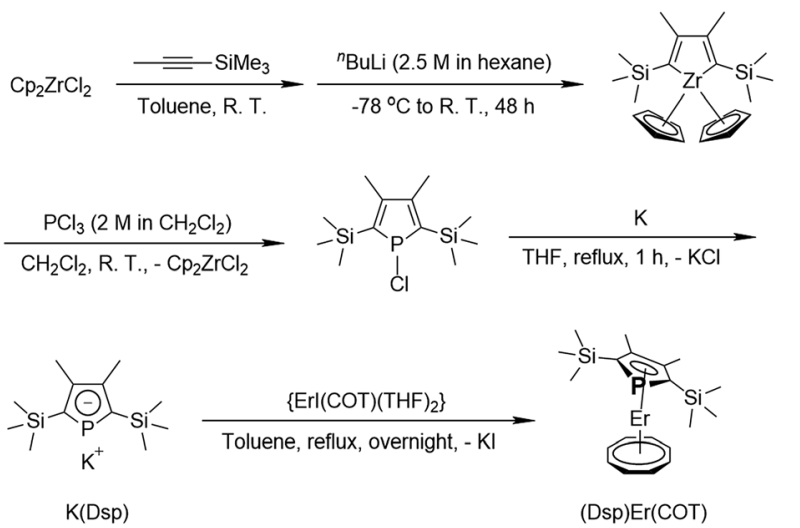

Scheme 1 Synthesis of (Dsp) Er(COT). variation of optical and magnetic properties. Alternating current (AC) magnetic susceptibility measurement of (Dsp) $\operatorname{Er}(\mathrm{COT})$ demonstrated a significant change of magnetic dynamics compared with its parent analogue $\left(\mathrm{Cp}^{*}\right) \operatorname{Er}(\mathrm{COT})$ (vide infra).

Following the work by François Nief and Louis Ricard ${ }^{25,27}$ with some modifications, we first get phospholyl potassium $\mathrm{K}(\mathrm{Dsp})$, which then reacts with $\operatorname{ErI}(\mathrm{COT})(\mathrm{THF})_{x}(x=2-3$, see the $\mathrm{ESI}_{\dagger}^{\dagger}$ ) in toluene under reflux to produce (Dsp)Er(COT) with insoluble KI (Scheme 1). Trying to precipitate $\mathrm{KCl}$ by reacting with $\{(\mathrm{THF}) \operatorname{Er}(\mathrm{COT})(\mu-\mathrm{Cl})\}_{2}$ is unsuccessful, although $\mathrm{K}(\mathrm{Dsp})$ can eliminate $\mathrm{Cl}^{-}$in $\left\{(\mathrm{THF})_{2} \mathrm{Nd}(\mathrm{COT})(\mu-\mathrm{Cl})\right\}_{2}$ (ref. 25) which is probably due to different acidity between light and heavy Ln(III) ions (vide supra). Orange single crystals suitable for X-ray diffraction analysis can be obtained by cooling the concentrated toluene solution of (Dsp) $\operatorname{Er}(\mathrm{COT})$ at $-30{ }^{\circ} \mathrm{C}$ for several days (anal. calc.: C, 45.59\%; H, 6.12\%; found: C, 45.73\%; H, 6.12\%.).

As depicted in Fig. 1, the single crystal structure of (Dsp) $\mathrm{Er}(\mathrm{COT})$ at $180 \mathrm{~K}$ (structure refined according to ref. 28) reveals itself as a double-decker structure, reminiscent of its $\mathrm{Cp}^{*}$ parent. ${ }^{29}$ It crystallizes in the $P 2_{1} / c$ space group. The nearest Er $\cdots$ Er distance is $7.832 \AA$. It's noteworthy that the COT $^{2-}$ ring is in static disorder as well with the ratios 0.56 and 0.44 (Fig. S4 in the ESI $\dagger$ ). The tilting angle between $\mathrm{Dsp}^{-}$and $\mathrm{COT}^{2-}$ planes is $10.5^{\circ}$. The distance from $\operatorname{Er}(\mathrm{III})$ to the five-membered ring is $2.321 \AA$, larger than that in $\left(\mathrm{Cp}^{*}\right) \operatorname{Er}(\mathrm{COT})(2.268 \AA)$, which crystallographically shows a weaker coordination between the two, yet $\operatorname{Er}(\mathrm{III})$ is much closer to $\mathrm{COT}^{2-}$ (1.686 $\mathrm{A}$ in (Dsp)Er(COT), $1.727 \AA$ in the $\mathrm{Cp}^{*}$ version and $1.875 \AA$ in $\left.\left[\operatorname{Er}(\mathrm{COT})_{2}\right]^{-}\right) .{ }^{30 a}$ The $\mathrm{Er}-\mathrm{C}\left(\mathrm{Dsp}^{-}\right)$bond lengths range from 2.635 to $2.645 \AA$, while $\mathrm{Er}-\mathrm{C}\left(\mathrm{COT}^{2-}\right)$ bond lengths are from 2.471 to $2.491 \AA$. The Er-P bond length is $2.793 \AA$, being close to the reported Er-P bond length. ${ }^{31}$ To the best of our knowledge, this is the first sandwich structure reported with a phospholyl ligand and $\mathrm{COT}^{2-}$ coordinating simultaneously to a heavy $\operatorname{Ln}(\mathrm{III})$.

We wonder if a slight change of only one coordinated atom could trigger a pronounced difference of magnetic properties. We resort to AC susceptometry which is often applied to probe magnetic dynamics. ${ }^{4}$ The out-of-phase component $\left(\chi_{M}^{\prime \prime}\right)$ of molar AC susceptibility for (Dsp)Er(COT) exhibits noticeable

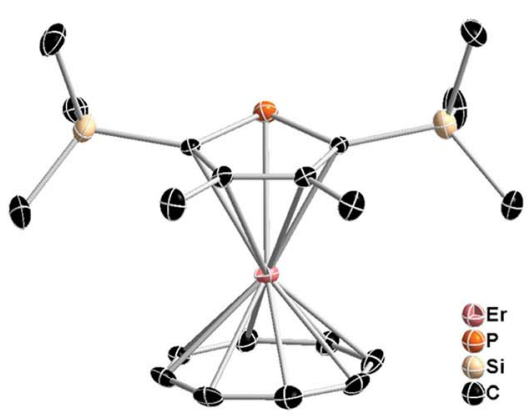

(a)

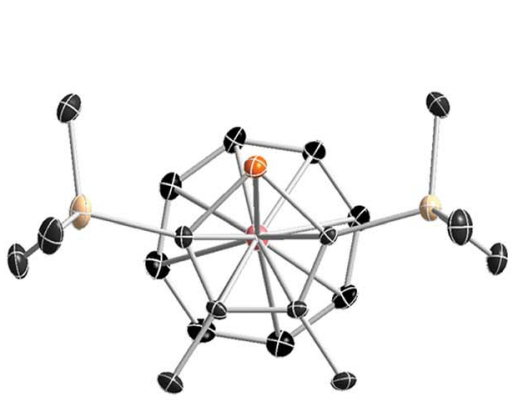

(b)

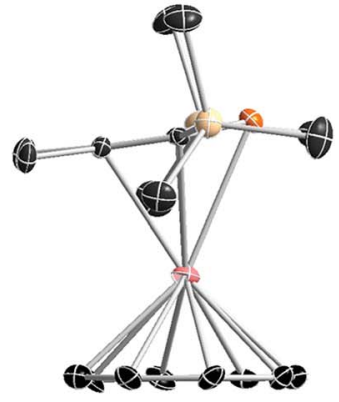

(c)

Fig. 1 Front view (a), top view (b) and side view (c) of the single crystal structure of (Dsp)Er(COT) with pink, orange, tan, and black ellipsoids (30\% possibility) representing $\mathrm{Er}, \mathrm{P}, \mathrm{Si}$, and $\mathrm{C}$, respectively (another disorder fragment of $\mathrm{COT}^{2-}$ is shown in Fig. S4 $\dagger$ ). Hydrogen atoms and another disordered part of $\mathrm{COT}^{2-}$ (Fig. S4†) have been omitted for clarity. Selected bond lengths: $\mathrm{Er}-\mathrm{P}=2.793 \AA ; \mathrm{Er}-\mathrm{C}\left(\mathrm{Dsp}{ }^{-}\right)=2.635-2.645 \AA ; \mathrm{Er}^{-}$ $\mathrm{C}\left(\mathrm{COT}^{2-}\right)=2.471-2.510 \AA$ 
frequency-dependence over 1 to $1000 \mathrm{~Hz}$ from 2 to $28 \mathrm{~K}$ under a zero applied DC field (Fig. 2). As with its prototype, this slow magnetic relaxation of (Dsp)Er(COT) unveils itself as a SIM. There is a single peak in the plot of $\chi_{\mathrm{M}}^{\prime \prime}$ versus $T$ at a given frequency while there are two for $\left(\mathrm{Cp}^{*}\right) \operatorname{Er}(\mathrm{COT})$. The narrow distribution of relaxation time $\tau(\alpha=0.01-0.2)$ from the fitting of the Argand $\operatorname{plot}^{32}$ (Fig. S10†) indicates almost a single relaxation despite the existence of two static disorder conformers which instead gives rise to two relaxation processes corresponding to two peaks of $\chi_{M}^{\prime \prime}$ in the measured temperature range for $\left(\mathrm{Cp}^{*}\right) \operatorname{Er}(\mathrm{COT})^{1}$.

A combination of an Orbach process and quantum tunnelling of magnetization (QTM) $\left(\tau^{-1}=\tau_{0}{ }^{-1} \exp \left[-\Delta /\left(k_{\mathrm{B}} T\right)\right]+\tau_{\mathrm{QTM}}{ }^{-1}\right.$, $\tau$ is the relaxation time) can fit the data of $\ln \tau$ versus $T^{-1}$ well

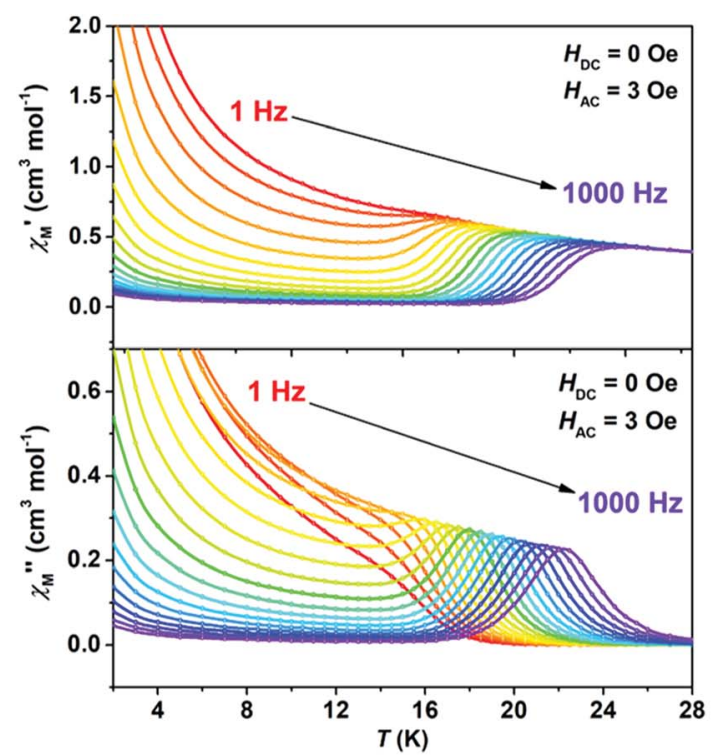

(a)

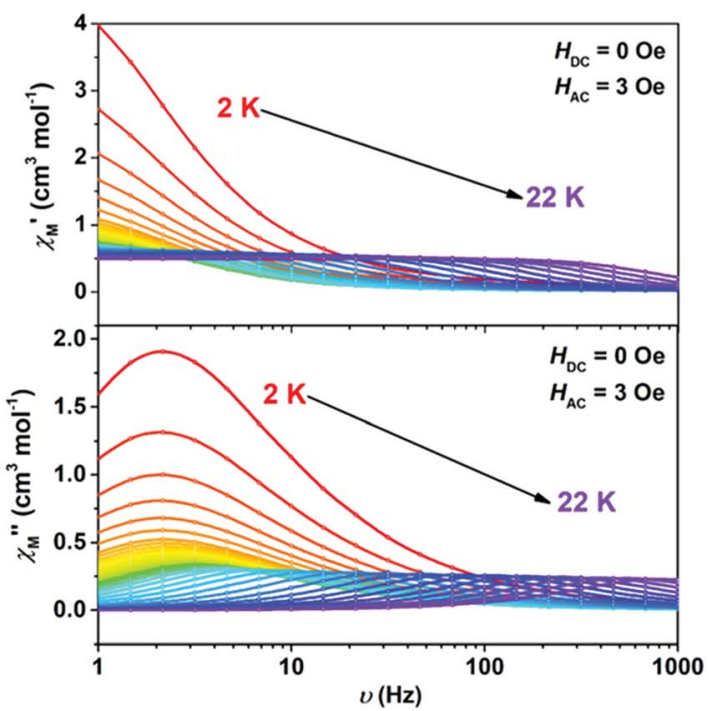

(b)

Fig. 2 Temperature (a) and frequency-dependence (b) of molar AC susceptibility (upper : $\chi_{M}^{\prime}$, lower : $\chi_{M}^{\prime \prime}$ ) for (Dsp)Er(COT) under a zero applied DC field over the temperature range of $2-28 \mathrm{~K}$ and the frequency range of $1-1000 \mathrm{~Hz}$.

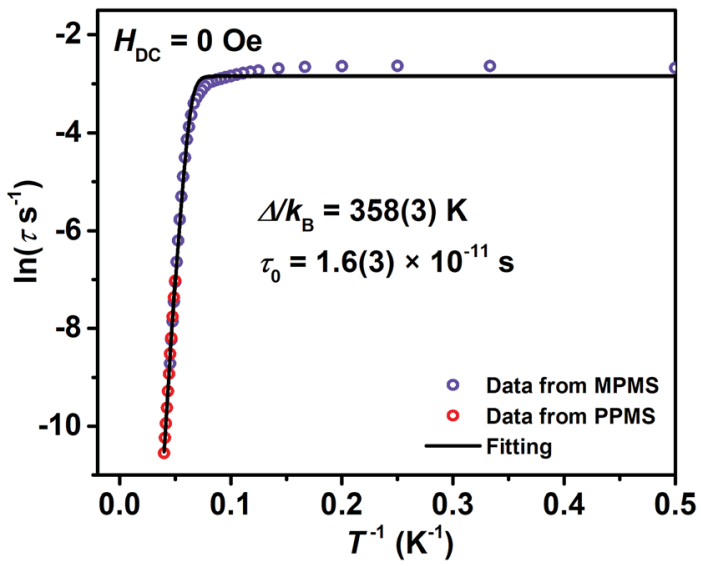

Fig. 3 Plot of natural log of relaxation time versus inverse temperature under a zero applied DC field. The purple and red circles represent the data from MPMS and PPMS, respectively. The black solid line represents the best fitting using a combination of Orbach and QTM processes. The fitting gives $\Delta / k_{\mathrm{B}}=358(3) \mathrm{K}$ and $\tau_{0}=1.6(3) \times 10^{-11} \mathrm{~s}$.

(Fig. 3). It demonstrates that the thermally activated Orbach process is dominant above $12 \mathrm{~K}$ and QTM considerably masks other possible relaxations below $10 \mathrm{~K}$. The fitting returns a relaxation barrier $\Delta / k_{\mathrm{B}}=358(3) \mathrm{K}$ which is much higher than that of $\left(\mathrm{Cp}^{*}\right) \operatorname{Er}(\mathrm{COT})(197,323 \mathrm{~K})^{1 a}$ and $\left[\operatorname{Er}(\mathrm{COT})_{2}\right]^{-}(206 \mathrm{~K})$, and among the highest ones in $\operatorname{Er}(\mathrm{III})$-based SIMs. ${ }^{30,33}$ Magnetic dynamics measurements were also performed under a $1000 \mathrm{Oe}$ DC field to effectively suppress the QTM (Fig. S12 $\dagger$ ). A similar workup to that described above gives $\Delta / k_{\mathrm{B}}=367$ (1) K (Fig. S13 $\dagger$ ).

The subsequent measurement of zero field cooled and field cooled magnetization (ZFC-FC) presents a divergence at about $8.5 \mathrm{~K}$ between the two curves (Fig. S7†), which reminds us of a probable magnetic hysteresis. As expected, typical butterflyshaped magnetic hysteresis loops in mesoscopic SMMs ${ }^{3,4}$ can be

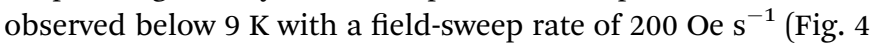
and $\mathrm{S} 8 \dagger$ ). At $2 \mathrm{~K}$, there is still a magnetic remnant of $0.3 \mathrm{~N} \beta$ at a zero field and the value of the coercive field $H_{c}$ is 55 Oe. The

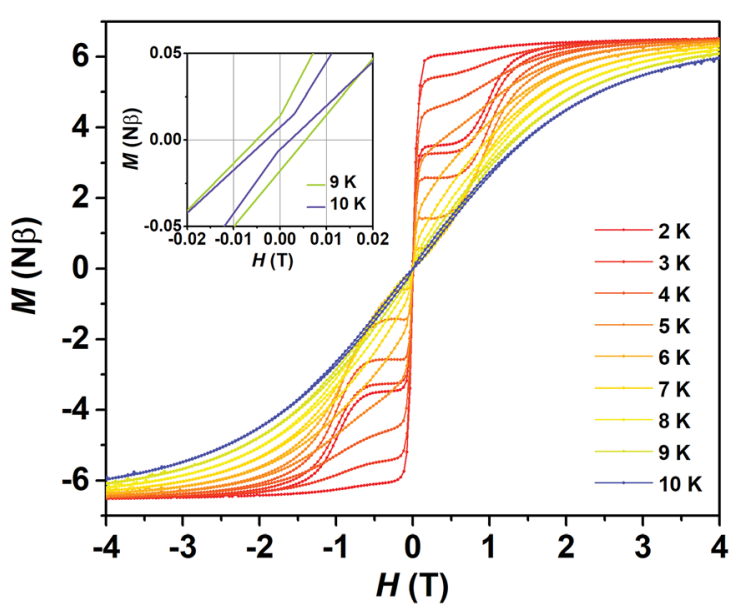

Fig. 4 Variable-field magnetization for (Dsp) $\operatorname{Er}(C O T)$ with a fieldsweeping rate of $200 \mathrm{Oe} \mathrm{s}^{-1}$. (Inset) Expanded view of the variablefield magnetization near the zero field at $9 \mathrm{~K}$ and $10 \mathrm{~K}$. 
magnetic blocking temperature $\left(T_{\mathrm{B}}\right)$ of about $9 \mathrm{~K}$ (Fig. S8 $\dagger$ ) is much higher than that of $(\mathrm{Cp} *) \operatorname{Er}(\mathrm{COT})\left(5 \mathrm{~K}, 550 \mathrm{Oe} \mathrm{min}^{-1}\right)$ and almost rivals that of $\left[\operatorname{Er}(\mathrm{COT})_{2}\right]^{-}\left(10 \mathrm{~K}, 0.78 \mathrm{mT} \mathrm{s}^{-1}\right) .^{30 a}$ This is a robust confirmation that (Dsp) $\operatorname{Er}(\mathrm{COT})$ is a magnet which can reserve its magnetization even under a zero field like a block magnet. The above results explicitly unveil (Dsp)Er(COT) as a SIM with a good performance.

Why does the seemingly weaker ligand field of $\mathrm{Dsp}^{-}$produce stronger anisotropy than $\left[\mathrm{Cp}^{*}\right]^{-}$? For one thing, we think that the phospholyl ligand and its parents $\mathrm{Cp}^{-}$and $\left[\mathrm{Cp}^{*}\right]^{-}$are more like axial ligands favorable for the oblate electron distribution of Dy(III) to stabilize its Ising-type $\mathrm{M}_{J}$ ground state ${ }^{34,35}$ as exemplified by plenty of excellent Cp-based Dy(III) SMMs. ${ }^{36}$ But they're unsuitable for prolate $\operatorname{Er}(\mathrm{III})$ under Ising-limit conditions. This sort of difference between Dy(III) and Er(III) originates from the opposite signs of axial crystal field parameters $\left(B_{2}^{0}\right.$ and $\left.B_{4}^{0}\right)^{30 b}$ for the two lanthanide ions. The moving away of the Dsp ligand from the axial electron cloud of $\operatorname{Er}(\mathrm{III})$ could reduce the electron repulsion. On the other hand, a large equatorial ligand such as the $\mathrm{COT}^{2-}$ ring with high rotational symmetry is suitable for prolate $\operatorname{Er}(\mathrm{III})$ to stabilize its $\mathrm{M}_{J}$ ground state as corroborated by $(\mathrm{Cp} *) \operatorname{Er}(\mathrm{COT})$ and $\left[\operatorname{Er}(\mathrm{COT})_{2}\right]^{-}$. The closer the $\operatorname{Er}(\mathrm{III})$ is to the $\mathrm{COT}^{2-}$ ring, the stronger the ligand field the -2 charged $\mathrm{COT}^{2-}$ exerts on $\operatorname{Er}(\mathrm{III})$, and hence the larger the anisotropic splitting of the ground $\mathrm{J}$ state. Although there are two $\mathrm{COT}^{2-}$ rings in $\left[\operatorname{Er}(\mathrm{COT})_{2}\right]^{-}$, 30 a the distance between $\operatorname{Er}(\mathrm{III})$ and $\mathrm{COT}^{2-}\left(d_{\mathrm{Er}-\mathrm{COT}}\right)$ becomes larger $(1.875 \AA)$ due probably to the repulsion between the two $\mathrm{COT}^{2-}$ rings which results in a weakened ligand field instead and its anisotropic energy barrier is lower than that of $\left(\mathrm{Cp}^{*}\right) \operatorname{Er}(\mathrm{COT})$. In this regard, the closer the $\mathrm{Er}(\mathrm{III})$ is to the $\mathrm{COT}^{2-}$ ring within a certain range, the lower and less mixed the ground state doublets are, making them closer to the Ising limit at least for the lowest Kramers doublets. Compared with $\left(\mathrm{Cp}^{*}\right) \operatorname{Er}(\mathrm{COT})$, the weak adhesion of $\operatorname{Er}(\mathrm{III})$ in (Dsp) $\operatorname{Er}(\mathrm{COT})$ with the phospholyl ligand leads to a shorter distance between $\operatorname{Er}(\mathrm{III})$ and $\mathrm{COT}^{2-}$ (vide supra) in order to maintain a balanced and conservative electrostatic potential of Er(III). So SIM performance improves as elaborated above in spite of lower symmetry (Table 1). We believe that $d_{\mathrm{Er}-\mathrm{COT}}$ plays an essential role in causing different magnetic dynamics between (Dsp)Er(COT) and (Cp*)Er(COT).

As a statistical induction, we have found the COT-based $\operatorname{Er}($ III) SIMs reported to-date and plotted each scattered point representing the data of $\Delta / k_{\mathrm{B}}$ versus $d_{\mathrm{Er}-\mathrm{COT}}$ (Fig. 5a). In a panoramic view, when the $\mathrm{COT}^{2-}$ ring moves gradually away from $\operatorname{Er}($ III), the barrier goes through a precipitous fall below 1.7 $\AA$, and then changes less with increasing $d_{\mathrm{Er}-\mathrm{COT}}$. In order to

Table 1 Comparison of structural metrics and energy barrier between $(\mathrm{Cp} *) \operatorname{Er}(\mathrm{COT})^{1 b}$ and (Dsp) $\operatorname{Er}(\mathrm{COT})$

\begin{tabular}{lll}
\hline & $(\mathrm{Cp} *) \operatorname{Er}(\mathrm{COT})$ & $(\mathrm{Dsp}) \operatorname{Er}(\mathrm{COT})$ \\
\hline Er-centroid $\left(\mathrm{COT}^{2-}\right) / \AA$ & $1.7267(3)$ & $1.6855(3)$ \\
Er-centroid (five-membered ring $) / \AA^{\mathrm{A}}$ & $2.2679(3)$ & $2.3220(3)$ \\
${\text { Tilting angle between the two rings }{ }^{\circ}}$ & 7.3 & 10.5 \\
$\Delta / \mathrm{K}$ & 197,323 & 358
\end{tabular}

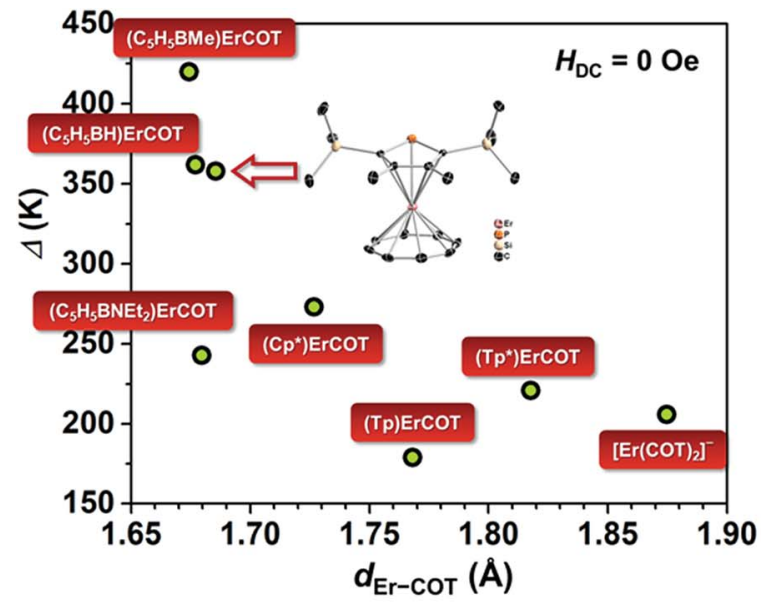

(a)

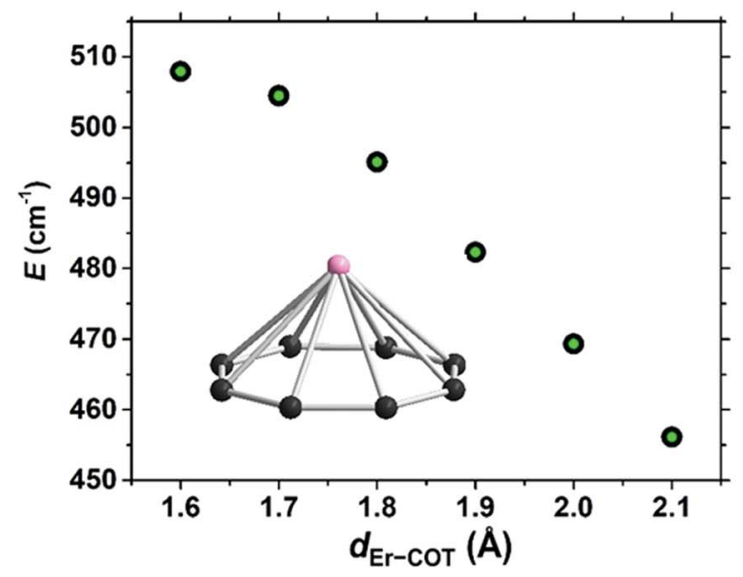

(b)

Fig. 5 (a) Scattered points representing the data of $\Delta / k_{\mathrm{B}} v s$. $d_{\mathrm{Er}-\mathrm{COT}}$ from reported COT-based Er(III) SIMs. ${ }^{1,30 a, 33,38}$ The data of (Cp*) Er(COT) are from the calculation based on the ligand field for easy comparison. $\left([T p]^{-}=\operatorname{tris}\left(1\right.\right.$-pyrazolyl)borate and $\left[\mathrm{Tp}^{*}\right]^{-}=\operatorname{tris}(3,5$-dimethyl-1-pyrazolyl)borate); (b) plot of energy barrier vs. series of $d_{\mathrm{Er}-\mathrm{COT}}$ for the hypothetical fragment $[\mathrm{Er}(\mathrm{COT})]^{+}$calculated based on $a b$ initio; inset: $[\mathrm{Er}(\mathrm{COT})]^{+}$.

theoretically understand the trend, we calculated the energy barrier of the model molecular fragment $[\operatorname{Er}(\mathrm{COT})]^{+}$with a different $d_{\mathrm{Er}-\mathrm{COT}}$ using the ab initio method $^{37}$ (Table S5; Fig. $5 \mathrm{~b}$ and S24†). Previous computation ${ }^{30 b}$ involved two $\mathrm{COT}^{2-}$ rings based on the single crystal structure of $\left[\operatorname{Er}(\mathrm{COT})_{2}\right]_{-}$. However, we think it's not a single factor story in which high negative charge repulsion between $\mathrm{COT}^{2-}$ rings may result in an unstable ground state within a certain distance (vide supra). So the result may not be very convincing if we only want to examine the relationship between $\Delta / k_{\mathrm{B}}$ and $d_{\mathrm{Er}-\text { Сот }}$. In our model with only one $\mathrm{COT}^{2-}$ ring, as expected, when $d_{\mathrm{Er}-\mathrm{COT}}$ becomes larger than $1.6 \AA$, the energy barrier goes down approximately in a linear way. The downtrend of the energy barrier with increasing $d_{\mathrm{Er}-\mathrm{COT}}$ in Fig. 5 shows that a short $d_{\mathrm{Er}-\mathrm{COT}}$ is conducive to a high energy barrier, and the chemically adjustable soft $\mathrm{P}$ atom in the five-membered ring is the pushing hand. 
From the above elaboration, we can see the main line clearly whereby the introduction of a soft $\mathrm{P}$ atom leads to a larger distance from $\mathrm{Er}(\mathrm{III})$ to the $\mathrm{Cp}$ analogue which reflects a weaker affinity between the two, and hence a shorter $d_{\mathrm{Er}-\text { СOT }}$ which enhances the ligand field and anisotropic splitting. So a higher energy barrier is possibly reached.

In this series, we have also examined (Dsp)Ln(COT) $(\mathrm{Ln}=\mathrm{Tb}$ (CCDC No. 1835954), Dy (CCDC No. 1835957), and Tm (CCDC No. 1835958)) among which (Dsp)Dy(COT) exhibits slow magnetic relaxation under a 2000 Oe applied DC field with $\Delta / k_{\mathrm{B}}$ $=57 \mathrm{~K}$ (Fig. S15 $\dagger$ ). (Dsp)Tm(COT) is also a field-induced SIM under a 2500 Oe applied DC field with an energy barrier of $109 \mathrm{~K}$ (Fig. S18†), which is almost the highest in Tm(III)-based SIMs ${ }^{38}$ so far.

\section{Conclusions}

We have successfully synthesized (Dsp) $\operatorname{Er}(\mathrm{COT})$ whose sandwiched single crystal structure is reported here for the first time. Compared with its parent compound (Cp*)Er(COT), the replacement of only one coordinated carbon atom on the cyclopentadienyl ligand by a softer phosphorus atom results in a considerable change of magnetic dynamics which returns a relaxation energy barrier of $358 \mathrm{~K}$ under a zero applied DC field and blocking temperature of $9 \mathrm{~K}$. Both manifest it as a better SIM than (Cp*)Er(COT). The essential reason mainly resides in the short distance between $\operatorname{Er}(\mathrm{III})$ and $\mathrm{COT}^{2-}$ caused by the weak affinity of $\operatorname{Er}(\mathrm{III})$ with $\mathrm{Dsp}^{-}$. Through the introduction of a softer coordinating atom, we have obtained a better $\operatorname{Er}($ III) SIM. Inspired by this work, we will continue to focus on introducing more soft $\mathrm{P}$ atoms and expect better $\operatorname{Er}(\mathrm{III})$-based SIMs.

\section{Conflicts of interest}

There are no conflicts to declare.

\section{Acknowledgements}

This work is supported by the National Natural Science Foundation of China (21621061, 21290171, 21571008 and 91422302), National Key R\&D Program of China (2017YFA0206301, 2017YFA0204903) and High-performance Computing Platform at Peking University. We sincerely thank Dr Ling Xu for helpful discussion on synthesis, Dr Yin-Shan Meng for discussion on magnetic measurements, and Mrs Zhi-Xian Wang, Mrs Xiu Zhang and Mr Ming-Xing Chen at the Analytical Instrumental Center of Peking University.

\section{Notes and references}

1 (a) S.-D. Jiang, B.-W. Wang, H.-L. Sun, Z.-M. Wang and S. Gao, J. Am. Chem. Soc., 2011, 133, 4730; (b) S.-D. Jiang, S.-S. Liu, L.-N. Zhou, B.-W. Wang, Z.-M. Wang and S. Gao, Inorg. Chem., 2012, 51, 3079.

2 (a) R. L. Carlin, Magnetochemistry, Springer-Verlag, Berlin, 1986; (b) O. Kahn, Molecular Magnetism, VCH, Weinheim,
1993; (c) C. Benelli and D. Gatteschi, Introduction to Molecular Magnetism: From Transition Metals to Lanthanides, Wiley-VCH, Weinheim, 2015.

3 (a) R. Sessoli, H.-L. Tsai, A. R. Schake, S. Wang, J. B. Vincent, K. Folting, D. Gatteschi, G. Christou and D. N. Hendrickson, J. Am. Chem. Soc., 1993, 115, 1804; (b) R. Sessoli, D. Gatteschi, A. Caneschi and M. A. Novak, Nature, 1993, 365, 141.

4 (a) D. Gatteschi, R. Sessoli and J. Villain, Molecular Nanomagnets, Oxford University Press, Oxford, 2006; (b) D. N. Woodruff, R. E. P. Winpenny and R. A. Layfield, Chem. Rev., 2013, 113, 5110; (c) J. M. Frost, K. L. M. Harriman and M. Murugesu, Chem. Sci., 2016, 7, 2470.

5 N. Ishikawa, M. Sugita, T. Ishikawa, S. Koshihara and Y. Kaizu, J. Am. Chem. Soc., 2003, 125, 8694.

6 S.-D. Jiang, B.-W. Wang and S. Gao, Struct. Bonding, 2015, 164, 111.

7 M. Urdampilleta, S. Klyatskaya, J.-P. Cleuziou, M. Ruben and W. Wernsdorfer, Nat. Mater., 2011, 10, 502.

8 (a) Y.-S. Ding, N. F. Chilton, R. E. P. Winpenny and Y.-Z. Zheng, Angew. Chem., Int. Ed., 2016, 55, 16071; (b) Y.-C. Chen, J.-L. Liu, L. Ungur, J. Liu, Q.-W. Li, L.-F. Wang, Z.-P. Ni, L. F. Chibotaru, X.-M. Chen and M.-L. Tong, J. Am. Chem. Soc., 2016, 138, 2829; (c) J. Liu, Y.-C. Chen, J.-L. Liu, V. Vieru, L. Ungur, J.-H. Jia, L. F. Chibotaru, Y.-H. Lan, W. Wernsdorfer, S. Gao, X.-M. Chen and M.-L. Tong, J. Am. Chem. Soc., 2016, 138, 5441.

9 (a) N. Ishikawa, M. Sugita, T. Okubo, N. Tanaka, T. Iino and Y. Kaizu, Inorg. Chem., 2003, 42, 2440; (b) M. A. AlDamen, J. M. Clemente-Juan, E. Coronado, C. Martí-Gastaldo and A. Gaita-Ariño, J. Am. Chem. Soc., 2008, 130, 8847; (c) S.-D. Jiang, B.-W. Wang, G. Su, Z.-M. Wang and S. Gao, Angew. Chem., Int. Ed., 2010, 49, 7448; (d) Lanthanides and Actinides in Molecular Magnetism, ed. R. A. Layfield and M. Murugesu, Wiley-VCH, Weinheim, 2015.

10 (a) F. Nief, Eur. J. Inorg. Chem., 2001, 891; (b) F. Nief, P. Riant, L. Ricard, P. Desmurs and D. Baudry-Barbier, Eur. J. Inorg. Chem., 1999, 1041; (c) P. Gradoz, D. Baudry, M. Ephritikhine, M. Lance, M. Nierlich and J. Vigner, J. Organomet. Chem., 1994, 466, 107; (d) P. Gradoz, C. Boisson, D. Baudry, M. Lance, M. Nierlich, J. Vigner and M. Ephritikhine, J. Chem. Soc., Chem. Commun., 1992, 1720. 11 (a) E. J. M. de Boer, I. J. Gilmore, F. M. Korndorfer, A. D. Horton, A. van der Linden, B. W. Royan, B. J. Ruisch, L. Schoon and R. W. Shaw, J. Mol. Catal. A: Chem., 1998, 128, 155; (b) S. J. Brown, X. Gao, D. G. Harrison, L. Koch, R. E. v. H. Spence and G. P. A. Yap, Organometallics, 1998, 17, 5445; (c) D. Barbier-Baudry, S. Heiner, M. M. Kubicki, E. Vigier and M. Visseaux, Organometallics, 2001, 20, 4207.

12 (a) P. Desmurs, M. Visseaux, D. Baudry, A. Dormond, F. Nief and L. Ricard, Organometallics, 1996, 15, 4178; (b) F. Nief and L. Ricard, Organometallics, 2001, 20, 3884.

13 R. Hoffmann, Angew. Chem., Int. Ed., 1982, 21, 711.

14 F. Mathey, J. F. Nixon and K. Dillon, Phosphorus: the Carbon Copy, Wiley, New York, 1998.

15 Phosphorous - Carbon Heterocyclic Chemistry. The Rise of a New Domain, ed. F. Mathey, Pergamon, Oxford, 2001. 
16 (a) E. Le Roux, F. Nief, F. Jaroschik, K. W. Törnroos and R. Anwander, Dalton Trans., 2007, 4866; (b) S. M. Cendrowski-Guillaume, G. Le Gland, M. Nierlich and M. Ephritikhine, Z. Kristallogr. NCS., 2002, 217, 35.

17 R. G. Pearson, J. Am. Chem. Soc., 1963, 85, 3533.

18 F. Jaroschik, T. Shima, X. Li, K. Mori, L. Ricard, X.-F. Le Goff, F. Nief and Z.-M. Hou, Organometallics, 2007, 26, 5654.

19 (a) F. Nief, D. Turcitu and L. Ricard, Chem. Commun., 2002, 1646; (b) D. Turcitu, F. Nief and L. Ricard, Chem.-Eur. J., 2003, 9, 4916; (c) F. Nief, B. T. de Borms, L. Ricard and D. Carmichael, Eur. J. Inorg. Chem., 2005, 637.

20 (a) F. Nief and L. Ricard, Organometallics, 2001, 20, 3884; (b) F. Nief and L. Ricard, J. Organomet. Chem., 1994, 417, 149.

21 (a) F. Nief, L. Ricard and F. Mathey, Polyhedron, 1993, 12, 19; (b) F. Nief and L. Ricard, J. Chem. Soc., Chem. Commun., 1994, 2723.

22 F. Jaroschik, F. Nief, X.-F. Le Goff and L. Ricard, Organometallics, 2007, 26, 3552.

23 F. Jaroschik, F. Nief and X.-F. Le Goff, Polyhedron, 2009, 28, 2744.

24 D. Turcitu, F. Nief and L. Ricard, Chem.-Eur. J., 2003, 9, 4916. 25 M. Visseaux, F. Nief and L. Ricard, J. Organomet. Chem., 2002, 647, 139.

26 S. M. Cendrowski-Guillaume, G. Le Gland, M. Nierlich and M. Ephritikhine, Eur. J. Inorg. Chem., 2003, 1388.

27 M. Westerhausen, M. H. Digeser, C. Gückel, H. Nöth, J. Knizek and W. Ponikwar, Organometallics, 1999, 18, 2491.

28 (a) O. V. Dolomanov, L. J. Bourhis, R. J. Gildea, J. A. K. Howard and H. Puschmann, J. Appl. Crystallogr., 2009, 42, 339; (b) L. Palatinus and G. Chapuis, J. Appl. Crystallogr., 2007, 40, 786; (c) G. A. Bain and J. F. Berry, J. Chem. Educ., 2008, 85, 532.

29 W. J. Evans, M. A. Johnston, R. D. Clarka and J. W. Ziller, J. Chem. Soc., Dalton Trans., 2000, 1609.

30 (a) K. R. Meihaus and J. R. Long, J. Am. Chem. Soc., 2013, 135, 17952; (b) L. Ungur, J. J. Le Roy, I. Korobkov, M. Murugesu and L. F. Chibotaru, Angew. Chem., Int. Ed., 2014, 53, 4413.

31 (a) P. W. Roesky, M. T. Gamer, M. Puchner and A. Greiner, Chem.-Eur. J., 2002, 8, 5265; (b) P. W. Roesky, M. T. Gamer and N. Marinos, Chem.-Eur. J., 2004, 10, 3537; (c)
M. T. Gamer and P. W. Roesky, Inorg. Chem., 2005, 44, 5963; (d) T. K. Panda, M. T. Gamer and P. W. Roesky, Inorg. Chem., 2006, 45, 910.

32 (a) K. S. Cole and R. H. Cole, J. Chem. Phys., 1941, 9, 341; (b) C. Dekker, A. F. M. Arts, H. W. de Wijn, A. J. van Duyneveldt and J. A. Mydosh, Phys. Rev. B: Condens. Matter Mater. Phys., 1989, 40, 11243.

33 Y.-S. Meng, C.-H. Wang, Y.-Q. Zhang, X.-B. Leng, B.-W. Wang, Y.-F. Chen and S. Gao, Inorg. Chem. Front., 2016, 3, 828.

34 J. Sievers, Z. Phys. B: Condens. Matter, 1982, 45, 289.

35 J. D. Rinehart and J. R. Long, Chem. Sci., 2011, 2, 2078.

36 (a) F. Tuna, C. A. Smith, M. Bodensteiner, L. Ungur, L. F. Chibotaru, E. J. L. McInnes, R. E. P. Winpenny, D. Collison and R. A. Layfield, Angew. Chem., Int. Ed., 2012, 51, 6976; (b) S. Demir, J. M. Zadrozny, M. Nippe and J. R. Long, J. Am. Chem. Soc., 2012, 134, 18546; (c) T. Pugh, F. Tuna, L. Ungur, D. Collison, E. J. L. McInnes, L. F. Chibotaru and R. A. Layfield, Nat. Commun., 2015, 6, 7492; (d) T. Pugh, A. Kerridge and R. A. Layfield, Angew. Chem., Int. Ed., 2015, 54, 4255; (e) T. Pugh, V. Vieru, L. F. Chibotaru and R. A. Layfield, Chem. Sci., 2016, 7, 2128; (f) T. Pugh, N. F. Chilton and R. A. Layfield, Angew. Chem., Int. Ed., 2016, 128, 11248; (g) F.-S. Guo, B. M. Day, Y.-C. Chen, M.-L. Tong, A. Mansikkamäki and R. A. Layfield, Angew. Chem., Int. Ed., 2017, 56, 11445; (h) C. A. P. Goodwin, F. Ortu, D. Reta, N. F. Chilton and D. P. Mills, Nature, 2017, 548, 439.

37 (a) G. Karlström, R. Lindh, P. Å. Malmqvist, B. O. Roos, U. Ryde, V. Veryazov, P. O. Widmark, M. Cossi, B. Schimmelpfennig, P. Neogrady and L. Seijo, Comput. Mater. Sci., 2003, 28, 222; (b) F. Neese, Wiley Interdiscip. Rev.: Comput. Mol. Sci., 2012, 2, 73; (c) L. F. Chibotaru and L. Ungur, J. Chem. Phys., 2012, 137, 064112; (d) L. F. Chibotaru, L. Ungur, C. Aronica, H. Elmoll, G. Pilet and D. Luneau, J. Am. Chem. Soc., 2008, 130, 12445; (e) F. Aquilante, et al., J. Comput. Chem., 2016, 37, 506.

38 Y.-S. Meng, Y.-S. Qiao, Y.-Q. Zhang, S.-D. Jiang, Z.-S. Meng, B.-W. Wang, Z.-M. Wang and S. Gao, Chem.-Eur. J., 2016, 22, 4704 . 